\title{
A concepção das ciências e do agir responsável dos estudantes face às mudanças climáticas ${ }^{1}$
}

\author{
Barbara Bader ${ }^{2}$ \\ Agnieszka Jeziorski ${ }^{3}$ \\ Geneviève Therriault ${ }^{4}$
}

\section{Resumo}

A escola vem sendo desafiada, cada vez mais na atualidade, pelas questões ambientais que, por serem tratadas em sala de aula, merecem ser enriquecidas pela concepção escolar das ciências e das práticas pedagógicas. Nesse sentido, e considerando as exigências dos programas escolares que incentivam os professores de ciências a ensinarem as mudanças climática de forma interdisciplinar e os professores de História a tratar esta Questão Ambiental Socialmente Viva com a preocupação de educar para a cidadania, concebemos e testamos uma abordagem interdisciplinar de ensino para os alunos do Ensino Médio de seis turmas escolares da cidade de Quebec. Inspirados na ilha de racionalidade proposta por Fourez, Maigain e Dufour (2002), o que se pretende é uma tentativa de renovação da forma escolar,

1 Tradução do francês por Silvia Laura Teixeira Gomes, mestre em Relações Internacionais pela PUC Minas. silviatgomes@yahoo.com.br

2 Ph.D. em Didática das Ciências, Universidade de Laval (UL), Québec, Canadá. Professora da Faculdade de Ciências da Educação, Universidade de Laval, (Québec, Canadá) barbara.bader@fse.ulaval.ca 3 Doutora em Didática, Université d'Aix-Marseille (France) e Universidade de Laval (Québec, Canadá). Desenvolve estágio de pós-doutorado na Universidade du Québec à Rimouski, Canadá.

agnieszka.jeziorski@gmail.com

$4 \mathrm{Ph}$. D. em Educação pela Universidade de Québec à Rimouski (UQAR), Montréal, Canadá. genevieve_therriault@uqar.ca 
mais interdisciplinar, na qual os alunos são relativamente autônomos. Os resultados aqui apresentados referem-se, particularmente, às concepções dos alunos sobre a natureza das ciências, tal como eles nos descreveram em entrevistas realizadas após o processo pedagógico. Especificamos, igualmente, os tipos de engajamento cívico que eles dizem, durante as entrevistas, privilegiar. Esses resultados traduzem uma maneira mais sutil de se pensar as ciências, por parte dos estudantes, e apontam para uma valorização real desse tipo de pedagogia.

Palavras-Chave: concepções sobre a natureza das ciências; ciências da educação; questões socialmente vivas; Ensino Médio; cidadania.

\title{
Student's conceptions of science and of responsible behavior regarding climate change
}

\begin{abstract}
Schools are increasingly challenged by current environmental issues that require an enrichment of how sciences and teaching practices can be conceived. In this sense, we aim for an interdisciplinary approach for teaching a "Socially acute questions" in science and history at the secondary level. It is an attempt to renew the school form in which students are more autonomous than average, and which proposes a more actual version of the nature of science, to see how students understand such preoccupations coming from the social studies of sciences. The teaching approach on climate change is presented briefly, as well as the main empirical results the reflect a more nuanced way of understanding science, being aware of limitations in terms of validity and potential debates and lead toward a real appreciation of this type of pedagogy. Another key element we present is how students react to these environmental issues and how they are making sense of their actions.
\end{abstract}

Keywords: conceptions of the nature of sciences; science education; "socially acute questions"; High School Students; civic engagement. 


\section{Introdução ${ }^{5}$}

Com o objetivo de estudar as concepções sobre a natureza das ciências (RICHARD; BARDER, 2010) por parte dos alunos do Ensino Médio, bem como suas formas de mobilização face à questão das mudanças climáticas, elaboramos e testamos uma sequência de ensino em seis turmas de uma escola da cidade de Quebec, em Ciência e Tecnologia do Meio Ambiente e em História e Educação para a Cidadania. Consideramos as exigências dos programas escolares, que preconizam um ensino das ciências ancorado nas principais questões ambientais da atualidade, e o tratamento das mudanças climáticas na história com a preocupação de educar para a cidadania.

Os resultados que apresentamos aqui se referem, particularmente, às concepções da natureza das ciências por parte dos alunos, tal como eles nos descrevem em entrevista após todo o processo educacional. Especificamos, igualmente, os tipos de engajamento cívico que eles dizem privilegiar, durante as entrevistas.

\section{Sobre a concepção escolar das ciências e de sua renovação}

A questão da renovação da concepção escolar das ciências é importante para a didática das ciências (ALBA; ORANGE, 2010). Enriquecer o que é feito na escola pelas considerações relativas às práticas de pesquisa atuais pode ser visto como uma forma interessante de envolver os alunos nessa área do conhecimento. É, também, essencial para prepará-los a tomar posição e debater de modo informado sobre as principais Questões Socialmente Vivas Ambientais (QSVA) (LEGARDEZ; SIMONNEAUX, 2006) ${ }^{6}$, questões

50 artigo aqui apresentado é uma versão modificada do artigo publicado, em francês, na revista Les Dossiers des Sciences de l'Éducation, n. 29, 203, p. 15-23, com o título Conception des Sciences e d’un agir responsable. 6 Segundo Legardez (2006), uma questão socialmente viva de caráter ambiental é triplamente viva: a) viva na sociedade, apresentando-se como um embate social e que produz debate, tanto no interior como exteriormente às instituições escolares; b) viva nos saberes de referência e suscita controvérsias entre os especialistas dos campos disciplinares ou ainda entre os experts dos campos profissionais; c) viva nos saberes escolares, no sentido que tanto os alunos como professores são a elas diretamente confrontados, sendo que os professores frequentemente se sentem desmunidos para tratá-las na escola, uma vez que sua concepção de ensino não lhe oferece condições de fazer face às mesmas. Em síntese, as Questões Socialmente Vivas Ambientais são portadoras de incertezas e são objeto de divergências, de disputas, de conflitos, e esses, tanto entre a comunidade científica, como na esfera pública. 
que mobilizam conhecimentos científicos incertos e muitas vezes contraditórios, conforme as diferentes posições entre os grupos. Sabe-se que muitos estudantes do Ensino Médio se interessam, fora do quadro escolar, pelo conhecimento científico e tecnológico avançados. Porém, frequentemente, apesar dessa curiosidade legítima, os conteúdos e formas de ensinar as ciências tendem a desmotivar-lhes (OSBORNE, 2003). A escola apresenta, habitualmente, os conhecimentos científicos bem estabelecidos, mas sem precisão quanto ao contexto de sua elaboração. Isso conduz a uma concepção empirista e desencarnada das ciências, relativamente passadista (BADER, 2011; BADER; RICHARD, 2010; DESAUTELS; LAROCHELLE, 1992; DRIVER et al., 1996; LEE; ROTH, 2003). Essa concepção escolar reforça a ideia de que as ciências e os seus representantes, os cientistas, são os únicos a "falar em nome da natureza" (GOUGH, 2004; WEINSTEIN, 2001). E, se as ciências são as únicas capazes de fazer essa leitura "leitura direta da natureza" (ALBA, 2009), os cientistas tornam-se, então, os únicos que podem legitimamente analisar e propor soluções aos problemas ambientais, que merecem, no entanto, uma abordagem democrática mais ampla. Os alunos não se sentirão, assim, realmente interrogados (BADER, 2003; POULIOT; BADER; THERRIAULT, 2010). Daí a importância em se renovar a concepção dos estudantes sobre as ciências, em particular a posição epistemológica que a subjaz (RICHARD; BADER, 2010).

Neste sentido, muitos pesquisadores recomendam hoje uma educação cidadã das ciências pela abordagem das QSVA (ALBA; GOMBERT, 2010; ALBE, 2009; KOLSTØ, 2001a; 2001b; LEGARDEZ; SIMONNEAUX, 2006; SADLER; CHAMBERS; ZEIDLER, 2004; SADLER, 2004). Além de proporcionar mais significado à aprendizagem dos conceitos científicos, tal abordagem contribuiria ao desenvolvimento de uma atitude mais crítica por parte dos alunos, desencadeando uma reflexão de caráter epistemológico quanto à natureza das ciências. Por mobilizar saberes não institucionalizados, socialmente situados e portadores de incertezas, o ensino das QSVA, nas aulas de ciências, é tido como um meio para enriquecer a compreensão das ciências por parte dos alunos do Ensino Médio e, a partir daí, no modo como eles se engajam no aprendizado das ciências. 


\section{Barreiras ao ensino das QSVA}

No sistema escolar atual, o ensino das QSVA não é óbvio. De fato, a ruptura com o "modelo pedagógico positivista que domina os saberes escolares" (TUTIAUX-GUILLON, 2011, p. 220) pode representar o risco de se ensinar uma questão ideologicamente muito carregada, o que pode levar à perda de significado e do desejo de aprender (LEGARDEZ; SIMONNEAUX, 2006). Nossa revisão bibliográfica permitiu identificar as barreiras já conhecidas a esse tipo de ensino. Destacamos algumas delas a seguir, tanto do ponto de vista das concepções dos professores e dos alunos, quanto das práticas de ensino habituais, obstáculos que consideramos ao conceber nossa abordagem de ensino das ciências e da história.

\subsection{Forma escolar}

Aparentemente, um obstáculo importante no ensino das QSVA reside na habitual forma escolar ${ }^{7}$. Em consequência, ensinar essas questões contribui para a dimensão de construção do conhecimento, além de envolver os alunos e prepará-los para o seu papel atual e futuro de cidadão (LANGE; VICTOR, 2011, p. 36). Nesse sentido, a relação professor-aluno é vista de forma radicalmente diferente e, em particular, as relações de autoridade geralmente privilegiadas em sala de aula (STEVENSON, 2007). O professor torna-se, assim, o guia de um projeto comum. Tal renovação diz respeito à postura epistemológica e aos gestos profissionais, tarefa que não é fácil, podendo levar a uma desestabilização da identidade profissional, especialmente no Ensino Médio, no qual a atividade docente é definida em função da formação disciplinar.

Além disso, dada a natureza das QSVA, uma abordagem interdisciplinar é necessária durante seu tratamento em sala de aula. Diversas pesquisas apontam a dificuldade em superar um certo confinamento disciplinar (AUDIGIER; TUTIAUX-GUILLON, 2008;

7 Elaborada no final dos 1979, a teoria sociológica da "forma escolar" articula um modo de organização da educação que forma, no Ocidente nos séculos XVI e XVII e que se caracteriza pela separação entre o universo da infância e da vida adulta, pela importância das regras na aprendizagem e um emprego do tempo bastante restrito e pela multiplicação dos exercíios permitindo aprender segundo esses regras (Vincent, Lahire et Thin, 1995). 
CORNEY; REID, 2007; MARTINAND, 2008, entre outros autores), e particularmente, em relacionar as dimensões científicas e as dimensões sociais das QSVA (URGELLI; SIMONNEAUX; LEMAREC, 2011), sobretudo no contexto da educação média. O ensino interdisciplinar das QSVA parece se confrontar com a hierarquia dos saberes disciplinares e com o receio dos docentes de se aventurarem no território dos professores de outras disciplinas (LUDWIG-LEGARDEZ; JEZIORSKI, 2010).

\subsection{A falta de problematização e de debate das QSVA}

Como observamos acima, as QSVA são portadoras de incertezas, além de cientificamente pouco estabelecidas. Portanto, sua utilização requer a integração de dúvidas e de interpretações plurais, privilegiando-se, por exemplo, o debate enquadrado (LEGARDEZ; GIRAL; CHAMBOREDON, 2008). Vários estudos indicam a tendência dos professores em evitar a problematização e as controvérsias em sala de aula, preferindo se referir aos cientistas e aos especialistas (ALBA, 2009). Parece que em vez de problematizar uma QSVA, os professores preferem neutralizála, conformando-se às representações dominantes. Referindo-se às diversas pesquisas empíricas sobre as intenções e as práticas declaradas dos professores de ciências ${ }^{8}$, Alba (2009) aponta a focalização nos fatos científicos em detrimento do tratamento dos aspectos políticos, sociais e éticos. A aceitação da incerteza científica parece difícil para os professores. Consequentemente, a discussão em sala de aula representa para eles um conflito de opiniões entre os alunos, uma situação difícil de gerir em termos de ética e de responsabilidade docente.

\subsection{Uma educação que privilegie os "pequenos gestos" cotidianos}

Muitas pesquisas ilustram que as metodologias mobilizadas para ensinar as QSVA são, em geral, fortemente redutoras e procuram levar os alunos a mudar seu comportamento. Segundo as indicações de professores-estagiários, com uma pedagogia que se concentra nos

8 A análise mobiliza os dados das pesquisas realizadas sobre o ensino das questões científicas socialmente vivas sobre a energia, a telefonia móvel, as mudanças climáticas. 
pequenos gestos ecológicos, corre-se "menos risco...". Estabelecer pequenos gestos cotidianos seria "mais fácil do que grandes projetos". E "muitos pequenos gestos acabariam por ter um impacto sobre o planeta" (LUDWIG-LEGARDEZ; JEZIORSKI, 2010). A redução das questões ambientais às ações cotidianas também é evidente para os alunos. Como exemplo, Freudiger (2010) mostra que os estudantes dão sentido às ações cotidianas como a separação de resíduos ou o plantio de árvores como parte das atividades escolares, porém, eles possuem dificuldades em dar a esse ato um significado mais global. Lebatteux e Legardez (2010) confirmam a centralização dos estudantes no ambiente próximo e cotidiano quando se trata de agir. Tal abordagem comportamental parece implicar em uma fraca conexão entre o conhecimento e os bons gestos, um dos maiores obstáculos para a reflexividade crítica.

\section{Uma abordagem de ensino interdisciplinar sobre as mudanças climáticas}

O ensino das QSVA enfrenta diversos obstáculos no contexto escolar, seja devido à posição epistemológica privilegiada das ciências, que aposta no ensino de conhecimentos certificados e não contextualizados, devido às incertezas e à complexidade dessas questões, da forma escolar que torna difícil o cruzamento das disciplinas escolares, da identidade profissional dos professores ou, ainda, da tendência a uma pedagogia comportamentalista, sem verdadeiras problematizações sobre os reais problemas subjacentes às questões ambientais. Conscientes desses desafios, projetamos uma abordagem de ensino interdisciplinar sobre as mudanças climáticas, a fim de ajudar os alunos a compreender melhor a complexidade dessa QSVA, para tomarem consciência que incertezas e controvérsias permanecem, e convidá-los a documentar uma prática de pesquisa atual sobre essa questão. Ao fim do projeto, eles tiveram que tomar uma posição por escrito sobre se a ciência poderia guiar nossas ações face às mudanças climáticas e definir quais seriam as ações responsáveis a serem estabelecidas.

Apostamos em uma abordagem pedagógica que envolve, sucessivamente, as mudanças climáticas na disciplina de Ciências e Tecnologias e na de História, do Ensino Médio, com a finalidade de 
cruzar duas áreas de conhecimentos complementares e abrir a análise dessa questão aos alunos em dimensões complementares.

Trata-se, aqui, de estudar as concepções da natureza das ciências dos alunos, no contexto dessa abordagem pedagógica, o que constitui uma contribuição original ao estudo do ensino das ciências e sobre as mudanças climáticas. Neste artigo, apresentamos alguns resultados a partir do processo de ensino realizado na disciplina de Ciências. Algumas precisões sobre a abordagem complementar realizada na História foram feitas em outros estudos (BADER; THERRIAULT; ARSENEAU, 2011). Em Ciências e Tecnologias, além de enriquecer o conhecimento dos alunos sobre os conceitos que aparecem no currículo escolar, incentivamos os alunos a documentar os aspectos controversos e as incertezas sobre as mudanças climáticas, com o objetivo de convidá-los a questionar suas concepções sobre as ciências. Eles deveriam, igualmente, documentar uma prática de pesquisa e definir como os pesquisadores fazem para estudar essa questão.

A estratégia pedagógica adotada foi inspirada na chamada $A$ ilha interdisciplinar de racionalidade (FOUREZ; MAINGAIN; DUFOUR, 2002). A ilha, ou a representação cujo processo de conceituação de uma QSVA conduz cada equipe de estudantes, é, de fato, o resultado de um trabalho que conta com a participação de diferentes disciplinas e saberes. Essa modelização também permite discussões e tomadas de decisão em relação ao problema particular em estudo, de acordo com o contexto específico e com o projeto da equipe ${ }^{9}$.

9 Estamos conscientes de que a abordagem proposta aos alunos não pode ser considerada como representando literalmente a da ilha de racionalidade, muito mais rica. Nossa abordagem é nela inspirada (1) convidando os alunos a explicarem suas ideias no início da atividade sobre as mudanças climáticas e a natureza das ciências (por escrito e depois de ouvirem um debate entre dois pesquisadores, que serão apresentado neste artigo); (2) pedindo para que cada equipe escolhesse um tema para aprofundar, ligado às mudanças climáticas; (3) convidando-os a refletir sobre a natureza das ciências, após haver documentado uma prática de pesquisa, uma controvérsia e incertezas que permanecem pertinentes; (4) ao documentar dois aspectos sobre a questão (social, política, econômica ou ética); (5) Validando suas proposições e posições com dois experts escolhidos anteriormente pela equipe de pesquisadores; (6) levando-se em consideração as respostas às duas perguntas iniciais sobre as ciências e o seu papel para tratar da questão das mudanças climática, por escrito e oralmente. Essa abordagem realizada no curso de Ciência e Tecnologia Ambiental foi prosseguida no curso de História pelos estudo das ações que a sociedade e o Estado do Quebec tomaram para lutar contra as mudanças climáticas. Essas diferentes etapas permitiram que os alunos respondessem às duas questões propostas integrando o conhecimento vindo, pelo menos, das duas disciplinas escolares, ao mesmo tempo em que ampliavam suas considerações para outras áreas de referência e tomando consciência do conjunto das posições das equipes durante as apresentações orais. Isso nos permitiu constatar um enriquecimento das conceituações sobre o tema nos textos produzidos, na direção de 
A abordagem interdisciplinar testada em seis grupos de Ciência e Tecnologia do Meio Ambiente do Ensino Médio durou sete períodos de ensino, de 75 minutos cada. Foram mobilizados dois professores de Ciências de uma escola secundária e uma professora de História. Ocorrida na cidade de Quebec (Quebec, Canadá), cerca de 200 alunos matriculados no Programa de Educação Internacional (IEP) ${ }^{10}$ participaram da pesquisa.

\subsection{Etapas da abordagem do ensino sobre as mudanças climáticas}

A abordagem proposta durante o curso de Ciência e Tecnologia Ambiental pedia aos alunos para responder às duas questões norteadoras seguintes: "Será que a ciência pode nos dizer como agir? O que devemos fazer diante da perspectiva das mudanças climáticas?". Ela se desenvolveu, nas duas classes, da forma seguinte.

Primeiramente, os professores apresentaram aos alunos o conjunto do projeto e suas diferentes etapas. Em seguida, foram recolhidas as concepções iniciais dos alunos sobre a questão das mudanças climáticas e eles assistiram a um debate fictício entre dois estudiosos que não compartilham as mesmas posições sobre a natureza das ciências, o estado atual do conhecimento sobre mudanças climáticas e as prioridades das pesquisas sobre essa questão controversa (BADER, 2003; BADER; RICHARD, 2010). Agrupados em equipes de três, os estudantes deveriam em seguida:

1) escolher um tema a explorar sobre as mudanças climáticas em relação com as duas questões norteadoras e começar a procurar informações. Eles deveriam, também, integrar os conteúdos científicos do currículo escolar de ciência e tecnologia, por meio do desenvolvimento de uma rede de conceitos relacionados com esses conteúdos;

2) documentar dois desafios (social, ambiental, político, econômico, etc.) relacionados ao tema;

\footnotetext{
uma análise mais interdisciplinar. Esse aspecto não é, contudo, objeto de uma análise empírica neste artigo, sendo abordado de maneira exploratória.

10 Esses alunos participavam do programa de educação internacional (PEI), cujo nome oficial é Programa do Primeiro Ciclo do Secundário (PPCS), de responsabilidade da Organização do Bacharelado Internacional (IB: http:/ / www.ibo.org/fr/). Esse programa é baseado em três grandes princípios: a abertura intercultural, a educação global e a comunicação. Para ser admitido, o estudante deve ter obtido uma média igual ou superior a $75 \%$.
} 
3) documentar um elemento de controvérsia, uma prática de pesquisa, assim como as incertezas persistentes sobre o seu tema. Uma seleção de textos sobre diversas facetas da questão climática, assim como uma grade de leitura, foi oferecida aos estudantes, a fim de apoiar suas pesquisas documentais sobre esses diferentes aspectos;

4) consultar dois especialistas para enriquecer um aspecto de sua representação sobre o tema escolhido e validar sua proposição (uma das especialistas convidadas era uma estudante de mestrado em Geografia especializada em modelos climáticos informatizados, a segunda era física e contava com muitos anos de experiência na área);

5) produzir uma síntese de duas páginas relatando sua representação do tema e apresentar oralmente os elementos importantes para toda a classe, assim como a forma como cada equipe propunha se envolver, ainda mais, com as questões relativas às mudança climática (engajamento cívico).

Além disso, no curso de História e Educação para a Cidadania, como uma extensão sintética dos conhecimentos em ciências, os estudantes pesquisaram sobre as medidas implementadas pelo Estado e pela sociedade no Quebec concernente à questão climática (um tema no currículo escolar de História) e um debate na aula de História foi realizado para que os alunos discutissem suas respectivas posições, apoiados em argumentos e apresentassem formas de ação em relação à questão em estudo.

Também adaptamos, tanto quanto permite nossa abordagem, nossa proposta às expectativas dos professores. Em particular, tínhamos a preocupação em não complicar as tarefas no final do ano letivo. Assim, fornecemos-lhes uma abordagem tipo "chave na mão", incluindo todos os documentos necessários, e limitamos a abordagem a sete períodos no curso de Ciências. Grupos de três estudantes foram formados, a pedido dos professores. Também tivemos que reduzir a carga de trabalho dos alunos fora do horário escolar. Finalmente, devemos mencionar que foram os professores que conduziram o processo em sala de aula, depois de receberem treinamento de um professor de ciências da escola, que também atuava como assistente de pesquisa nesse projeto, e foi responsável pelo estabelecimento de elos entre os professores e a equipe de pesquisadores. 


\section{$4 \mathrm{O}$ protocolo de entrevista e as questões abordadas}

Este estudo tem como objetivo investigar as concepções da natureza das ciências por parte dos estudantes do Ensino Médio que participaram de uma abordagem de ensino em classe de Ciência e Tecnologia e de História. Apresentamos aqui alguns resultados, com base em 12 entrevistas feitas com os alunos no final do projeto, em grupos de três. Ao todo, 36 alunos foram envolvidos, cuja idade média é de 16 anos.

Essas entrevistas semiestruturadas, com duração de aproximadamente 45 minutos cada, permitiram discutir com os alunos as diferentes dimensões da sua concepção da natureza das ciências, que apresentamos, abaixo, alguns elementos.

Os alunos também compararam a abordagem experimentada às aulas habituais de ciências. Foram especialmente citadas a dinâmica do trabalho em equipe, as diretrizes de realização, a compreensão dos conceitos científicos, a fala dentro do grupo, o interesse e o empenho pessoal durante o processo e o papel do professor de ciências nesse contexto. As questões permitiam aos alunos expressarem sua opinião sobre tal abordagem, seus pontos fortes e aqueles a serem melhorados. O interesse dos estudantes em relação às questões ambientais e das mudanças climáticas, em particular, também foi discutido. Os dados coletados foram processados manualmente e uma análise temática foi realizada (PAILLE; MUCCHIELLI, 2008), com a ajuda do software NVivo 9, que ajudou a identificar temas e subtemas.

\section{Alguns resultados}

A seguir apresentaremos alguns resultados relacionados aos principais temas que emergem da análise temática. Será discutida, inicialmente, a avaliação dos alunos da abordagem pedagógica proposta. Algumas diferenças identificadas pelos alunos entre essa abordagem e as aulas de ciências habituais serão abordadas na sequência. Finalmente, serão apresentados os dados recolhidos a propósito das concepções da natureza das ciências por parte dos estudantes de Ciências e de suas 
formas de se mobilizar em relação às mudanças climáticas.

\subsection{O interesse pela abordagem pedagógica proposta}

De modo geral, podemos afirmar que a maioria dos estudantes entrevistados gostou da abordagem pedagógica sobre as mudanças climáticas, conforme fora proposta em ciências. Nas entrevistas, por 46 vezes, e em 11 das 12 entrevistas analisadas, os alunos manifestaram interesse por essa abordagem, enquanto em apenas seis momentos, em quatro das entrevistas, os alunos enfatizaram sua falta de interesse por esse processo. Em mais da metade das entrevistas, eles disseram apreciar o tema por eles escolhido, consideraram que a abordagem feita é interessante, que se retém o conhecimento com certa profundidade. Muitos gostaram do fato de serem relativamente independentes na realização do trabalho e de poderem discutir questões originais sobre as mudanças climáticas que, em geral, são pouco tratados em sala de aula.

\section{Os temas que as equipes trataram foram:}

- A conferência de Copenhague (controvérsia política e econômica)

- O estudo do fitoplânctom e os diferentes resultados conforme as práticas de pesquisa (estudo de imagens de satélites e estudos em laboratórios de amostras submetidas a condições específicas)

- A controvérsia sobre a governança da passagem do Noroeste (estudo das geleiras por meio de imagens de satélites e estudos das calotas polares)

- A utilização de combustíveis fósseis e dos dados meteorológicos

- As ligações entre as mudanças climáticas e os desastres naturais

- A homogeneização dos dados sobre o clima

- O envolvimento dos países em desenvolvimento no Protocolo de Quioto

- As causas e consequências da desertificação

- O declínio das populações de salmões: mudanças climáticas ou pesca excessiva? 
- Os biocombustíveis como solução para as mudanças climáticas?

- Os animais australianos em perigo: causado pelo turismo ou pelas mudanças climáticas?

\subsection{Comparação com os cursos de ciências regulares}

Algumas questões se colocam sobre a aprovação dessa forma de ensinar as ciências, em comparação com os cursos de ciências regulares: "Foi diferente ou não de suas aulas de ciências habituais? Especifique.".

Parece que, de modo geral, os estudantes consideram que, em um curso de ciências normal, o professor apresenta o material demasiadamente rápido. E, em comparação, o que emerge da opinião dos alunos quanto aos pontos fortes dessa abordagem é o aprofundamento do tema, uma vez que eles podem estabelecer mais ligações e realizar uma síntese a partir dos conhecimentos por eles pesquisados durante o processo. Esse método lhes permitiria "compreender" ao em vez de "aprender de cor", como é geralmente o caso. De acordo com os alunos, eles retêm mais desse processo de ensino interdisciplinar. O que também se difere é que, para fazer esse trabalho, os grupos se viam obrigados a se comunicar e a terem reais discussões de grupos, ao contrário dos projetos de ciências habituais, no qual os alunos distribuem as tarefas pedidas no início e, finalmente, cada um realiza uma parte do trabalho em grupo, sem verdadeiro compartilhamento de conhecimento entre os membros. Os alunos seriam, portanto, mais comprometidos com essa forma de aprendizagem do que nos cursos de ciências habituais, no qual o professor "passa" a matéria.

Os alunos também tomam consciência de que essa abordagem, pelo modo como os temas e as apresentações orais são preparados, lhes permitem compreender melhor o assunto e explicá-lo. Eles acreditam que, assim, eles lembram mais o que aprenderam. O que não seria o caso se apenas redigissem um texto ou tomassem notas, como ocorre em um curso mais tradicional.

A diversidade de temas tratados constitui outra diferença notável que a maioria dos estudantes parece ter apreciado. No caso dos cursos 
habituais, quando os alunos estão engajados em um projeto de ciências, todos os grupos abordam, geralmente, o mesmo assunto. Aqui, os alunos dizem gostar do fato de terem tido a oportunidade de escolher livremente um tema diferente, relacionado às mudanças climáticas para, em seguida, aprofundá-lo. Isso os teria permitido tomar consciência da complexidade da questão das mudanças climáticas e enriquecer seus conhecimentos sobre vários aspectos complementares.

\subsection{A concepção de ciências dos estudantes, algumas características}

A abordagem pedagógica proposta aos estudantes pretendia ser uma oportunidade de se estudar e de enriquecer suas compreensões sobre a natureza das ciências. Nesse sentido, observamos que os seguintes itens foram incluídos nessa abordagem: (1) um debate fictício entre dois cientistas que não concordam sobre as prioridades de pesquisa sobre mudanças climáticas e se embasavam em uma postura epistemológica, sobre estudos empíricos, sobre publicações reconhecidas e sobre diferentes considerações éticas (BADER, 2003). Procurava-se, com isso, introduzir no processo pedagógico certos aspectos da construção social das ciências, os elementos de debate entre os pesquisadores, os aspectos polêmicos, mas também a importância da validação pelos pares, das publicações dos resultados, bem como a afirmação da credibilidade do pesquisador por meio da participação de uma instância reconhecida, pois eles produzem os dados graças a grandes subsídios (LATOUR, 2001); (2) cada um dos grupos deveria documentar uma prática pesquisa relativa ao tema por eles escolhido, para aprofundar as questões em relação às mudanças climáticas ("prática de pesquisa", entendida aqui como os métodos, geralmente empíricos mas não apenas, permitindo aos pesquisadores coletar dados); (3) eles deveriam igualmente documentar uma controvérsia; (4) identificar as incertezas que poderiam permanecer. Finalmente, a partir dessa documentação do tema, eles respondiam por escrito e oralmente às duas questões norteadoras do início. As entrevistas que realizamos ao final do projeto nos permitiram retrabalhar com os alunos sua compreensão sobre esses diferentes elementos. 
No começo do processo, para o conjunto dos estudantes, a noção de "prática de pesquisa" colocou um problema. Os alunos não entendiam do que se tratava, sendo necessário que os professores especificassemna. Posteriormente, vários se disseram muito interessados em documentar esse aspecto do tema, além de haver apreciado saber como os pesquisadores fazem para chegar a novos conhecimentos.

Eu não sabia antes. Eu realmente não pensava sobre isso, sobre como os cientistas fazem para encontrar seus dados. Então, e sim, foi interessante saber como eles fazem. Quero dizer, isto se soma à nossa compreensão sobre as mudanças climáticas, pois é certo que é interessante saber isto. (Entrevista 6)

Os alunos também enfatizam que o processo os fez perceber que os cientistas nem sempre concordam entre si ao estudarem um mesmo assunto. Essa ideia é nova para eles, e encontramos, em seus comentários, um desconforto, muitas vezes documentado, diante da possibilidade de que dois pesquisadores que estudam um mesmo assunto possam chegar a conclusões distintas (ver, por exemplo, BADER, 2003; DRIVER et al., 1996), o que parece dificilmente concebível quando se representa as ciências como descrições empíricas precisas dos fenômenos naturais. Essa ideia encontra-se neste extrato de entrevista que comenta o fato de dois cientistas que estudam as mudanças climáticas discordarem entre si: "Se você estiver procurando por evidências na natureza, você deveria encontrar a mesma evidência que alguém que busca as mesmas evidências" (Entrevista 2).

Note-se que, na mesma entrevista, o trecho seguinte ilustra bem como a abordagem proposta pode enriquecer o pensamento crítico e a concepção sobre o que significa fazer ciência para alguns estudantes:

- [...] Não podemos aceitar qualquer coisa. [...] eles nos mostram certas coisas na TV, eles dizem que acontece tal fato. [...] Como eles chegaram a essa conclusão? Podemos ver, estudando as práticas de pesquisa, o que é que pode ser o mais confiável.

- [...] em um laboratório, era a minha imagem de pesquisador.

- Eu não pensava que ele pode apenas olhar imagens de satélite e que isso seja feito assim.

- [...] no fundo, [se] o objetivo [do processo] é mostrar que a ciência não é absoluta. Bem, foi bem-sucedido por isso. (Entrevista 2)

Ao mesmo tempo em que pareciam mais críticos diante da questão 
das mudanças climáticas, mais conscientes de sua complexidade, certos limites do conhecimento científico e das diferentes estratégias que são parte integrante da ciência, os alunos valorizam o trabalho dos pesquisadores sobre a questão. Note-se que eles reinvestiram seus novos conhecimentos sobre a natureza da ciência, sobretudo, a ideia de "prática de pesquisa" em sua concepção habitual da produção do conhecimento científico, empírico e realista: "Bem, imagino que o objetivo dos pesquisadores é serem o mais preciso e imparcial possível, o que os levam a ter práticas de pesquisa que são [...] comprovadas." (Entrevista 9).

Para eles, os cientistas são atores credíveis que têm a legitimidade necessária para orientar a população na direção de soluções:

- [...] quando um cientista diz tal fato sobre as mudanças climáticas, o mundo vai ouvi-lo porque ele é credível.

- Então, eu acho que eles têm, sobretudo, um poder de influência sobre a população.

- Bem, isso ajuda as pessoas a agirem mais e eles também fornecem pistas sobre como agir.

- Quanto mais os cientistas falam, mais as pessoas vão agir. (Entrevista 9)

Ao mesmo tempo sublinham, em outra entrevista, a importância de se informar e de não acreditar imediatamente no que foi dito sobre as mudanças climáticas.

- Mas eu não sabia que havia pontos de vistas assim, eu acreditava que todo mundo pensava que era o ser humano o responsável [...].

- [...] mas isso me fez perceber que você não pode simplesmente acreditar, você precisa se informar. (Entrevista 10)

\subsection{Formas de envolvimento cívico}

Uma das perguntas da entrevista era sobre o debate entre os dois pesquisadores que expressaram seu desacordo no que diz respeito às ações a serem tomadas em relação às mudanças climáticas (debate que os alunos ouviram no início do processo). Eis aqui a pergunta que deu origem aos resultados apresentados: "Vários grupos responderam, após o debate entre os dois pesquisadores, que agiriam mesmo havendo incertezas e que não sabemos tudo sobre as mudanças climáticas. O que você acha? Sendo assim, por que continuar a realizar ciências em relação 
ao clima? Sobre o que você vai se embasar para avaliar o impacto de suas ações?". A TAB. 1, abaixo, apresenta as principais categorias relacionadas ao tema do engajamento cívico.

TABELA 1 - Formas de envolvimento dos cidadãos

\begin{tabular}{l|c|c}
\hline Categorias & $\begin{array}{c}\text { Número de } \\
\text { entrevistas }\end{array}$ & $\begin{array}{c}\text { Número de } \\
\text { afirmações }\end{array}$ \\
\hline Pequenas ações verdes & 9 & 20 \\
Eles não sabem sobre quais conhecimentos se & 8 & 12 \\
baseiam suas ações & 5 & 8 \\
Eles não sabem sobre a pertinência de suas ações & 7 & 8 \\
Não devemos esperar saber tudo antes de agir & 6 & 8 \\
Precisamos continuar as pesquisas & 5 & 6 \\
Eles consideram que não possuem muita força & & \\
\hline
\end{tabular}

Fonte: Elaborada pelas autoras.

Como podemos constatar pela leitura da TAB. 1, os alunos, ao lidarem com seu engajamento cívico diante dos desafios das mudanças climáticas, referem-se, principalmente, às ações que eles executam cotidianamente, tais como a reciclagem, a utilização da bicicleta ou de ônibus e a compostagem (adubo orgânico). Assim, dentre as doze entrevistas analisadas, nove entrevistas contêm declarações que tratam dessas ações em um total de vinte enunciados. Por exemplo, um aluno responde à pergunta mencionando que faz compostagem (adubo orgânico), usa carona e utiliza o transporte público.

Bem, sim, parece que... alguém que é religioso, ele vai acreditar em sua religião. Ele vai acreditar em suas concepções, essas coisas e, então, ele vai realizar suas ações em função disso. Conosco é um pouco assim em relação à ciência. Realizamos nossas ações com base no que sabemos, no que achamos que é correto de acordo com a ciência, faça que é isso. Por exemplo, como eu dizia, eu faço muito composto [adubo orgânico], porque a ciência [diz] que isso ébom, fato é que é provavelmente por isso que nós damos carona, que eu utilizo o transporte público. Já é alguma coisa...é isso, eu escuto muito a ciência. (Entrevista 3)

Os alunos também mencionaram em doze ocasiões, em oito das doze entrevistas, que compreendem apenas uma parte do conhecimento científico subjacente às suas ações. A esse respeito, um estudante diz: 
Eu acho que, frequentemente, são conceitos gerais que retornam. Por exemplo, você apaga a luz para economizar energia. Você sabe, você não precisa ir buscar mais longe, o que é a energia que você economiza, mas você sabe que você faz. Mesmo caso para fazer reciclagem, ela vai impedir que se cortem árvores. As árvores, é o que nos permite ter o ar, você não vai procurar o princípio da fotossíntese, você sabe que é isto que faz o ar. Mesmo caso para o tanque. Ele faz o CO2, do CO2 ruim... Você sabe por que você faz isso, para evitar alguma coisa. Você não procura saber como isso funciona, concretamente. (Entrevista 4)

Apesar dessa falta de conhecimento científico, os alunos dizem que é preciso passar à ação, pois as ações recomendadas não podem, a seus olhos, resultarem em impactos negativos maiores sobre o meio ambiente. Segue um exemplo desse tipo de intenção ligada aos pequenos gestos.

Isso não pode, isso não pode estar errado, admitamos a reciclagem $e$ tudo isso. Mesmo que a gente não saiba tudo o que isso pode fazer, que a gente não saiba as consequências, isso não pode, isso não pode estar errado, isso não pode ser prejudicial. Você sabe, eu quero dizer, só pode ser melhor. (Entrevista 5)

Outra razão para tomar medidas, segundo os estudantes, é o caráter imprevisível das pesquisas científicas relacionadas às mudanças climáticas. Assim, alguns alunos sublinham que, uma vez que não podemos saber o momento das descobertas científicas, não devemos esperar por elas, sob o risco de que seja tarde demais para agir. Aqui está um trecho de entrevista que apoia essa ideia: "Você não pode saber quando irá descobrir algo novo. Então, bem, eu acho que não devemos esperar que seja tudo desenvolvido antes de fazer alguma coisa porque, caso contrário, talvez seja tarde demais." (Entrevista 1).

Enquanto alguns estudantes se questionam sobre a relevância de suas ações ou consideram não ter grande poder, outros esclarecem que não devemos esperar tudo conhecer antes de agir. Em conexão com essa ideia, segundo a qual a ação continua a ser importante quando tratamos das mudanças climáticas, os alunos mencionaram em oito ocasiões, nas doze entrevistas, que é preciso prosseguir com as pesquisas. Aqui está um trecho que ilustra bem essa ideia:

Mas, eu também, pessoalmente, eu acho que é importante continuar a investir em pesquisas, porque existem vários pontos que ainda são 
controversos em ciências. É importante saber exatamente o que deve ser feito, porque se a gente se diz "nós sabemos o que devemos fazer, é isso, isso, isso", e então, finalmente, nos damos conta, três anos depois, que nós apenas lançamos ideias no ar e que nós apenas machucamos ainda mais o planeta, bem, você sabe, ao mesmo tempo não estaremos mais à frente, ao contrário, estaremos ainda mais recuados. Por isso, é importante continuar a investir em pesquisa, mas não devemos nos impedir [de agir] em relação ao que estamos certos de que ajuda o meio ambiente. (Entrevista 3)

Embora se referindo a alguns conhecimentos adquiridos a partir da abordagem pedagógica sobre as mudanças climáticas, como o fato de fazer referência às incertezas que permanecem em relação à questão das mudanças climáticas, ou de mencionar que existem controvérsias, a posição dos alunos nos permite apontar diferentes formas de mobilizar as ciências quando é chegada a hora de tomar uma atitude. Alguns alunos simplesmente confiam no que é preconizado pela "ciência", chegando mesmo a compará-la a uma "religião", na qual acreditamos, mas sem parecer querer aprofundar o conhecimento como tal (Entrevista 3); outros, ao mesmo tempo que parecem reconhecerem os limites do conhecimento científico, não querem aprofundar a questão, e se baseiam, muitas vezes, em um conhecimento incorreto sem sabê-lo, ainda que digam agir com base nisso (Entrevista 4); outros invocam um certo princípio de precaução (devemos agir apesar das incertezas, Entrevistas 1 e 5). E, para alguns, devese prosseguir com as pesquisas, o que conduzirá, inevitavelmente, a um conhecimento bem estabelecido, capaz de orientar as ações nesse sentido, agindo desde o presente em função do que sabemos "ser bom para o meio ambiente". Esse ponto de vista sobre as divergências e as controvérsias entre os cientistas passa pela necessidade de mais pesquisas que levarão, necessariamente, à verdade, é uma posição já bem documentada, característica da atual concepção das ciências e de uma concepção realista do conhecimento (BADER, 2001; POTTER, 1996), aqui reconduzida.

\section{Conclusão}

Esses poucos elementos nos permitem pensar que a abordagem pedagógica interdisciplinar testada na aula de ciências deve ser reconduzida. Nossos resultados ilustram que esse tipo de pedagogia 
motiva os alunos e lhes permitem aprofundar suas reflexões ao mesmo tempo em que se tornam mais conscientes das diferentes facetas dessa complexa questão. Suas concepções sobre o trabalho dos pesquisadores foram enriquecidas pela consideração das práticas de pesquisa e dos elementos controversos relacionados com a questão do clima, o que é novo para eles. Os alunos enfatizam, ademais, que eles agiam face às mudanças climáticas, privilegiando as ações cotidianas ao seu alcance, ainda que sem serem capazes de definir seu real impacto. A maioria deles se remete aos especialistas e aos discursos corriqueiros, privilegiando a ideia de que a soma das pequenas ações acabará por surtir um impacto sobre o problema em pauta.

Note-se aqui que a reflexão dos estudantes também foi enriquecida durante as aulas de História e Educação para a Cidadania, sobretudo no que concerne às medidas realmente tomadas pelo governo e pela sociedade do Quebec sobre a questão das mudanças climáticas. As equipes expuseram oralmente, em seguida, a sua posição e seus depoimentos testemunham claramente que eles haviam enriquecido as suas análises sobre o problema e as possibilidades de ação a serem empreendidas. Para isso, vários grupos reconheceram que o Estado e a sociedade do Quebec criaram diversas ações para lidar com esse desafio, porém acreditam que é possível fazer ainda mais. As soluções imaginadas são muitas, tratamse, sobretudo, de "pequenos gestos verdes", mas também de ações que cabem ao Estado, assim como à sociedade do Quebec. O envolvimento dos jovens e dos cidadãos também é, segundo eles, muito importante, tanto na escola como em suas comunidades.

Essa forma de ensinar as ciências, apresentando-as como associadas a um contexto específico, convidando os alunos a definir concretamente o modo como os pesquisadores atuam na coleta de dados e esclarecendo, igualmente, as áreas de incerteza e controvérsia, parece motivar a maioria dos alunos entrevistados. Embora, inicialmente, o interesse pela questão das mudanças climáticas fosse relativamente pequeno, o fato de abordar o problema de forma a permitir que cada grupo escolhesse um tema para aprofundar e apoiá-los em sua busca documental, pareceu interessar à maioria dos estudantes. Nossos resultados não nos permitem 
compreender os pontos de vista da minoria dos estudantes que não se interessaram por esse trabalho. No entanto, eles apontam, certamente, para um interesse nesse tipo de abordagem pedagógica. Considerações sobre as incertezas que ainda cercam certos conhecimentos sobre as mudanças climáticas, sobre as controvérsias que permanecem e sobre as formas de se fazer ciência sobre o clima foram apresentados nos discursos coletados, evidência sobre a natureza das ciências que os estudantes reconheceram não suspeitar no início do processo. Deve-se ressaltar, porém, que eles incorporaram essas novas considerações sobre o que significa fazer ciências em sua concepção habitual, empírica e realista, valorizando, geralmente, a experiência científica como fonte de conhecimento legítimo sobre as mudanças climáticas. Essa concepção da natureza das ciências, que também encontramos nas colocações dos alunos sobre as formas como se autorresponsabilizam face às mudanças climáticas, apoiam-se em certa crença no que as ciências preconizam sobre a questão climática, sem problematizar as implicações. 


\section{Referências}

ALBE, V. Enseigner des controverses. Rennes: Presses Universitaires de Rennes, 2009.

ALBE, V.; GOMBERT, M.-J. Intégration scolaire d'une controverse socioscientifique contemporaine : savoirs et pratiques d'élèves pour appréhender les savoirs et pratiques de scientifiques. Recherches en didactiques des sciences et des technologies, v. 2, p. 103-126, 2010.

ALBE, V.; ORANGE, C. Sciences des scientifiques et sciences scolaires. Recherches en didactiques des sciences et des technologies, v. 2, p. 19-26, 2010.

ARSENEAU I. La conception des sciences d'élèves de 4ème secondaire dans le contexte d'une démarche inspirée de "l'îlot de rationalité » sur la question des changements climatiques. Mémoire de maîtrise en didactique des sciences. Université Laval. Québec, 2012.

ASTOLFI, J. P. Les questions vives en question? Préface. Dans A. LEGARDEZ; SIMONNEAUX, L. (Dir.), L'école à l'épreuve de l'actualité, enseigner les questions vives. Paris: ESF, 2006. p. 9-12.

AUDIGIER, F. Concepts de base et compétences-clés pour l'éducation à la citoyenneté démocratique. Projet "Éducation à la citoyenneté démocratique ». Conseil de l'Europe: DGIV/EUD/CIT, 2000.

AUDIGIER, F.; TUTIAUX-GUILLON, N. Compétences et contenus. Les curriculums en questions. Bruxelles: De Boeck, 2008.

BADER, B. Etude de conversations estudiantines autour d'une controverse entre scientifiques sur la question du réchauffement climatique. 2001. Thèse (Doctorat en Sciences de L'Éducation ) - Faculté des sciences de l'éducation, Université Laval, Québec, Canada, 2001. 
BADER, B. Controverse scientifique et expression rhétorique de croyances sur les sciences. LAFORTUNE, Dans L. et al. (Dir.). Conceptions, croyances et représentations en maths, sciences et technos. Sainte-Foy: Presses de l’Université du Québec, 2003. p. 175-197.

BADER, B. Rapprochement interdisciplinaire entre une éducation aux sciences citoyenne et l'éducation relative à l'environnement : points de vue de chercheurs et formations des enseignants. SAUVÉ, Dans L.; ORELLANA, I.; VAN STEENBERGHE, É. (Dir.). Le croisement des savoirs au cour des recherches en éducation relative à l'environnement.. Université du Québec à Montréal, Montréal: Acfas, Cahiers scientifiques, 2005. p. 109-119.

BADER, B. Education à l'environnement dans une société du risque : la conception des sciences privilégiée de l'éducation au développement durable. BADER, Dans B.; SAUVÉ, L. (Dir.). Éducation, environnement et développement durable: vers une écocitoyenneté critique. Québec : Les Presses de l’Université Laval - Collection L'espace public, 2011. p. 223-250.

BADER. B., THERRIAULT, G. \& ARSENEAU, I.. Présentation d'une démarche d'enseignement interdisciplinaire au secondaire (sciences et histoire) sur les changements climatiques pour des élèves de secondaire IV. In: CONFÉRENCE SUR INVITATION PRÉSENTÉE LORS DE L'ÉCOLE D’ÉTÉ EN ÉDUCATION ET DÉVELOPPEMENT DURABLE, août, 2011. Université Laval, Québec.

CORNEY, G.; REID, A. Student teachers' learning about subject matter and pedagogy in education for sustainable development. Environmental Education Research, v. 13, n. 1, p. 33-54, 2007.

DÉSAUTELS, J.; LAROCHELLE, M. Autour de l'idée de science. Itinéraires cognitifs d'étudiants et d'étudiantes. Sainte-Foy, Québec: Presses de l'Université Laval, 1992. 
DRIVER, R. et al. Young people's images of science. Buckingham, UK: Open University Press, 1996.

FOUREZ, G., MAINGAIN, A.; DUFOUR, B. Approches didactiques de l'interdisciplinarité. Bruxelles: De Boeck Université, 2002.

FREUDIGER, N. Comparaison de représentations d'élèves suisses et indiens sur le développement durable et le réchauffement climatique. Actes du congrès de l'Actualité de la recherche en éducation et en formation (AREF). 2010. Genève. Repéré à: <https:/ / plone2.unige.ch/aref2010>. Accès: 12 sep. 2010.

GOUGH, N. Living in a material world. SCOTT, Dans W.; GOUGH, S. (Dir.). Key issues in sustainable development and learning. A critical Review. London: Routledge Falmer, 2004. p. 236-240.

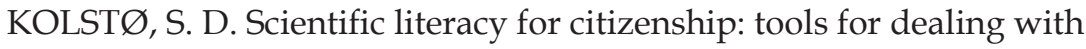
the sciencedimension of controversial socioscientific issues. Science Education, v. 85, p. 291-310, 2001a.

KOLSTØ, S. D. 'To trust or not to trust,...'-pupils' ways of judging informationencountered in a socio-scientific issue. International Journal of Science Education, v. 23, p. 877-901, 2001b.

LANGE, J. M.; VICTOR, P. Un nouveau métier: éduquer au développement durable. LaRevueDurable, v. 42,p. 36-39, 2011.

LATOUR, B. Le métier de chercheur. Regard d'un anthropologue. 2. ed. Paris: Institut National de la Recherche Agronomique, 2001.

LEBATTEUX, N.; LEGARDEZ, A. L'éducation au développement durable dans un lycée professionnel français en demarche d'agenda 21. Identification d'obstacles a partir du discours d'élèves éco-délègues. Actes du congrès de l'Actualité de la recherche en éducation et en formation 
(AREF). 2010. Genève. Repéré à: <https:/ / plone2.unige.ch/ aref2010>. Acèss: 8 oct. 2010.

LEE, S.; ROTH, W-M. Science and the Good Citizen: community based scientificliteracy. Science Technology and Human Values, v. 28, n. 3, p. 403-424, 2003.

LEGARDEZ, A. Enseigner des questions socialement vives. Quelques points de repères. LEGARDEZ, Dans A.; SIMONNEAUX, L. (Dirs.). L'école à l'épreuve de l'actualité. Enseigner les questions socialement vives. Paris: ESF, 2006. p. 19-31.

LEGARDEZ, A.; SIMONNEAUX, L. L'école à l'épreuve de l'actualité. Enseigner les questions socialement vives. Paris: ESF, 2006.

LEGARDEZ, A.; GIRAL, J.; CHAMBOREDON, M. C. Le débat argumenté: une pédagogie efficiente pour la co-construction de savoirs environnementaux critiques? Rapport de recherche 2006-2008 pour l'ADEME et le Conseil Régional PACA. Marseille: Université de Provence - UMR ADEF et Conseil Régional PACA, 2008.

LUDWIG-LEGARDEZ, A.; JEZIORSKI, A. Enquête sur l'existence d'une représentation sociale du Développement Durable et de l'Éducation au Développement Durable chez des professeursstagiaires. In: COLLOQUE INTERNATIONAL SUR L'ÉDUCATION AU DÉVELOPPEMENT DURABLE ET À LA BIODIVERSITÉ : CONCEPTS, QUESTIONS VIVES, OUTILS ET PRATIQUES, octobre, 2010. Digne les Bains, France.

MARTINAND, J.-L. Environnement et interdisciplinarité: paradoxes dans le champ éducatif. Natures Sciences societies, v. 16, p. 1-2, 2008.

OSBORNE, J. Attitudes towards science: a review of the literature and its implications. International Journal of Science Education, v. 25, n. 9, p. 
1.049-1.079, 2003.

PAILLÉ, P.; MUCHIELLI, A. L'analyse qualitative en sciences humaines et sociales. Paris: Armand Collin, 2008.

POULIOT, C.; BADER, B.; THERRIAULT, G. The notion of the relationship to knowledge: a theoretical tool for research in science education. Journal in Environmental and Science Education, v. 5, n. 3, p. 239-264, 2010.

POTTER, J. Representing reality: discourse, rhetoric and social construction. Sage Publications, 1996.

RICHARD, V.; BADER, B. Re-presenting the social construction of sciences in light of the propositions of Bruno Latour: for a renewal of the school conception of science in secondary schools. Science Education, v. 94, n. 4, p. 743-759, 2010.

SADLER, T. D. informal reasoning regarding socioscientific issues: a critical review of research. Journal of Research in Science Teaching, v. 41, n. 5, p. 513-536, 2004.

SADLER, T. D.; CHAMBERS, F. W.; ZEIDLER, D. L. Student conceptualisations of the nature of science in response to a socioscientific issue. International Journal of Science Education, v. 26, n. 4, p. 387-409, 2004.

STEVENSON, R. B. Schooling and environmental education: contradictions in purpose and practice. Environmental Education Research, v. 13, n. 2, p. 139-153, 2007.

THERRIAULT, G.; BADER, B. Démarche d'enseignement interdisciplinaire en sciences au secondaire. Un débat sur les changements climatiques pour une éducation citoyenne. Nouvelle 
CSQ - Bulletin du CRIRES. Printemps. 2009. Repéré à: <http:/ / www. csq.qc.

net/index.cfm/2,0,1676,9703,2299,0,html>. Accès: 6 jui. 2010.

TUTIAUX-GUILLON, N. Le développement durable en France. Suffit-il de prescrire une question vive pour qu'elle existe à l'école? LEGARDEZ, Dans A.; SIMONNEAUX, L. (Dir.). Développement durable et autres questions d'actualité. Questions socialement vives dans l'enseignement et la formation. Dijon: Educagri Editions, 2011. p. 215-228.

URGELLI, B.; SIMONNEAUX, L.; Le MAREC, J. Complexité, controverse et médiatisation dans l'enseignement d'une question socialement vive. Le cas du réchauffement climatique. LEGARDEZ, Dans A.; SIMONNEAUX, L. (Dir.). Développement durable et autres questions d'actualité. Les questions socialement vives dans l'enseignement et la formation. Dijon: Educagri Editions, 2011. p. 67-88.

VINCENT, G.; LAHIRE, B.; THIN, D. Sur l'histoire et la théorie de la forme scolaire. VICENT, Dans G. (Dir.). L'éducation prisonnière de la forme scolaire? Scolarisation et socialisation dans les sociétés industrielles. Lyon: Presses Universitaires de Lyon, 1994. p. 11-48.

Recebido em 10/12/2013 Aprovado em 30/06/2014 